\title{
ESTÉTICA E CONSUMO: ESTUDANDO DUAS TRIBOS URBANAS CARIOCAS
}

\section{ESTHETIC AND CONSUMPTION: STUDYING TWO URBAN TRIBES CARIOCAS}

\author{
Recebido em 28.05.2012 Aprovado em 31.01.2013 \\ Avaliado pelo sistema double blind review \\ DOI: http://dx.doi.org/10.12712/rpca.v7i1.172
}

\section{Leticia Casotti}

leticia@coppead.br

Instituto de Pós-Graduação e Pesquisa em Administração (COPPEAD) da Universidade Federal do Rio de Janeiro - Rio de Janeiro - RJ, Brasil.

\section{Marina Farina}

marinafaria86@hotmail.com

Instituto de Pós-Graduação e Pesquisa em Administração (COPPEAD) da Universidade Federal do Rio de Janeiro - Rio de Janeiro - RJ, Brasil.

\section{Bruno Lino}

marinafaria86@hotmail.com Instituto de Pós-Graduação e Pesquisa em Administração (COPPEAD) da Universidade Federal do Rio de Janeiro - Rio de Janeiro - RJ, Brasil.

\section{Gustavo Americano}

marinafaria86@hotmail.com

Instituto de Pós-Graduação e Pesquisa em Administração (COPPEAD) da Universidade Federal do Rio de Janeiro - Rio de Janeiro - RJ, Brasil.

\section{Resumo}

A pesquisa foi motivada pela crescente importância dos estudos sobre o fenômeno do tribalismo urbano para o Marketing. Alguns desses estudos indicam que produtos e marcas podem ser apropriados pelos membros da tribo para a criação de uma identidade. Nesse contexto, definiu-se como objetivo deste estudo investigar e confrontar padrões estéticos e práticas de consumo adotadas por duas tribos urbanas identificadas com o dia e com a noite na cidade do Rio de Janeiro. A tribo do dia foi escolhida a partir da praia pela importância social, cultural e econômica que as praias assumem no Rio de Janeiro. Já a tribo da noite foi composta por frequentadores de bailes de black music. A análise desses grupos sugere que eles apresentam padrões estéticos específicos e distintos, que servem como forma de identificação entre os membros de cada grupo. Os resultados também apontaram que o consumo de determinados produtos está relacionado com os valores de ligação das tribos investigadas.

Palavras-chave: Tribos urbanas. Estética. Práticas de consumo.

\begin{abstract}
The research was motivated by the growing importance of studies about the phenomenon of urban tribalism to the marketing area. Some of these studies indicate that products and brands may be appropriated by members of the tribe to create an identity. In this context, was defined as objective of this study investigate and confront aesthetic standards and consumption practices that are adopted by two urban tribes identified with the day's tribe and night's tribe in the city of Rio de Janeiro. The tribe of the day is the beach's tribe because of the social, cultural and economic value that the beaches have in Rio de Janeiro. The tribe of the night was composed of people that usually go to black music's party. Analysis of these groups suggests they present specific and distinct aesthetic patterns, which serve as identification between members of each group. The results also showed that consumption of certain products is related to the tribe's values of connection.
\end{abstract}

Keywords: Urban tribe. Aesthetic. Consumption habits. 


\section{Introdução}

Motivadas, sobretudo pela busca do sentimento de pertencimento - tido como perdido desde o advento da modernidade - indivíduos se engajam em toda a sorte de movimentos grupais (COVA \& COVA, 2002). Surgem assim as tribos ou comunidades urbanas, que se estruturam a partir de uma rede entre pessoas que se conectam por valores de ligações como lugares, indivíduos, produtos e marcas (COOPER, McLOUGHLIN \& KEATING, 2005).

Os artigos escritos por Cova e por seus co-autores fazem uma ligação importante entre o que os cientistas sociais ou filósofos como Mafezzolli (2006) e Bauman (2003) trazem do conceito das tribos pós-modenas e os estudos da área de Marketing, mais especificamente de Comportamento do Consumidor. No Brasil esses trabalhos parecem ter sido inspiração para algumas pesquisas encontradas em periódicos nacionais e anais de congresso (BARBOZA \& SILVA, 2012; BARBOZA \& AYROSA, 2010; CARVALHO, HEMAIS \& MOTTA, 2001; HELAL \& PIEDADE, 2010; SEGABINAZZI, NIQUE \& PINTO, 2011; SILVA, COSTA \& CARVALHO, 2010).

Com o reconhecimento do surgimento das tribos, estudiosos em Marketing passaram a investigar padrões de consumo dessas comunidades, buscando entender o papel de produtos e serviços para a criação de processos de identificação entre seus membros (JURISIC \& AZEVEDO, 2011). Nesse sentido, pesquisas feitas em outros países (COVA, 1997; COVA, KOZINETS \& SHANKAR, 2007) e no Brasil (BARBOZA \& SILVA, 2012; HELAL \& PIEDADE, 2010; SILVA, COSTA \& CARVALHO, 2010) apontam para o surgimento de subculturas de consumo, nas quais as identidades grupais e individuais encontram-se relacionadas com as práticas de consumo. Para Barboza e Ayrosa (2010) determinados bens podem ser consumidos como forma de diferenciação e expressão. Os lugares frequentados pelos membros da tribo também são importantes para a construção da identidade do grupo (CERCHIARO et al., 2012). Pereira e Ayrosa (2010), a seu turno, sugerem que as práticas de consumo podem revelar identidades estigmatizadas para as outras pessoas.

O estudo de tribos urbanas se insere na proposta de Arnould and Thompson (2005) de criação de uma Teoria da Cultura de Consumo - CCT (Consumer Culture Theory). Assim estudar tribos pode ser visto como parte de uma nova proposta de pensamento e prática de marketing que entende as comunidades como importantes na criação de valores de consumo (Schau, Muniz e Arnoul, 2009). Maffesoli (2006) aponta como principais pilares do tribalismo a ética, o costume e a estética. Sobre a ética, o autor enfatiza que se trata do cimento que fará com que diversos elementos de um dado conjunto formem um todo; o costume corresponde ao conjunto dos usos comuns que permitem a tribo reconhecer-se como um grupo social; a estética se refere à faculdade comum de sentir e experimentar. No que diz respeito à estética, as tribos urbanas costumam seguir padrões para unir seus membros e para diferenciar-se de outras tribos (FREHSE, 2006). Roupas e acessórios são elementos importantes para a criação de padrões estéticos, o que faz com que esse tipo de consumo esteja atrelado às regras informais presentes nessas tribos (Mc CRACKEN, 2003; VIEIRA, 2007).

A presente pesquisa tem por objetivo investigar e confrontar a estética e as práticas de consumo adotadas por duas tribos urbanas na cidade do Rio de Janeiro sendo uma identificada com o dia e a outra identificada com a noite na cidade do Rio de Janeiro. No estudo, a tribo do dia está caracterizada como o grupo de frequentadores habituais do trecho da praia de Ipanema localizado entre o Posto 9 e o Posto 10, enquanto a tribo da noite está representada pelo grupo de frequentadores de bailes charm embalados por black music.

A tribo do dia foi escolhida a partir da praia não só pela importância social, cultural e econômica que as praias assumem no Rio de Janeiro, mas também pelo fato de a praia ser o valor de ligação entre pessoas de diversos locais do Rio, particularmente das áreas mais nobres da cidade (BALSA, 
2005). Ou seja, a praia é o elemento que une essas pessoas fazendo com que elas possam a princípio ser analisados como uma tribo (COVA, 1997).

A escolha da praia de Ipanema deveu-se a sua importância histórica e também por sido citada como um exemplo de espaço de diferentes tribos urbanas pelo sociólogo francês Michel Maffesoli (2006) em seu livro "O Tempo das Tribos".

Com relação à tribo da noite, cabe observar que a black music de origem norte-americana faz parte da cultura carioca desde os anos 1970 (ALVES, 2010). No Rio, os bailes de música black constituem espaços de elaboração da identidade de seus frequentadores (MARTINS, 2005). Ao pesquisar diversos gêneros musicais, Béhague (2006) mostrou que a música é muitas vezes o principal valor de ligação que une tribos urbanas. Note-se, contudo, que a revisão de literatura indicou diferenças entre os cariocas que apreciam os diferentes subgêneros de black music, razão pela qual optou-se por caracterizar os membros da tribo da noite como frequentadores de bailes de charme, ficando de fora do escopo da pesquisa o funk ou o hip hop, subgêneros de black music estudados em trabalhos envolvendo tribos cariocas há pelo menos duas décadas (HASENBALG \& SILVA, 1992; VIANNA, 1990).

Na próxima seção, apresenta-se a revisão de literatura dividida em quatro subseções: tribos urbanas; tribos do dia e da noite; padrões estéticos das tribos; e consumo e tribos. Na seqüência, são detalhados os procedimentos metodológicos seguidos para a execução da pesquisa, para que, na seção seguinte, sejam apresentados os principais achados. $\mathrm{Na}$ ultima parte do artigo são desenvolvidas considerações finais e recomendações para estudos futuros.

\section{Tribos Urbanas}

O conceito pós-moderno de tribo refere-se ao renascimento de valores arcaicos relacionados ao senso de identificação, à religiosidade, ao sincretismo e a aspectos grupais de narcisismo (COVA, 1997). Para Maffesoli (2007), o tribalismo permite que seja revivido o arquétipo comunitário da aldeia. Adicionalmente, Cova (1996) e Cova e Cova (2002) defendem que as características arcaicas das tribos pós-modernas podem ser observadas uma vez que as pessoas não se agrupam em função de aglutinadores sociais modernos e racionais tais como profissões, mas em decorrência de uma dimensão não racional e arcaica que envolve emoção e paixão. Ainda assim, subsistem diferenças fundamentais entre as tribos arcaicas e as pós-modernas, pois as primeiras caracterizavam-se como permanentes e totalizantes, em função da exclusividade de pertencimento de seus membros a uma única tribo, da limitação geográfica, da união por laços de parentesco e do dialeto comum (BONNEMAIZON, COVA \& LOUYOT, 2007). Nas tribos urbanas contemporâneas, por sua vez, uma mesma pessoa pode pertencer a muitas tribos (FREHSE, 2006).

Tendo por alicerce o pensamento sociológico sobre a aparente tentativa da queda do individualismo no mundo contemporâneo acompanhada de uma volta aos valores comunitários (MAFFESOLI, 2006), bem como a emergência de movimentos grupais que buscam recriar vínculos sociais deteriorados desenvolve-se a perspectiva do marketing tribal (BONNEMAIZON, COVA \& LOUYOT, 2007; COVA, 1996; MAFFESOLI, 2007).

As tribos pós-modernas, em consonância com Cova e Cova (2002), são unidas por sentimentos compartilhados e símbolos específicos. Nelas, as pessoas podem reforçar valores e compartilhar experiências (SCHOUTEN \& ALEXANDER, 1995). Para Dionísio, Leal e Moutinho (2008), a busca por padrões dentro das tribos é principalmente uma tentativa de se diferenciar de outros grupos. Em um mesmo espaço geográfico, diversas tribos podem ser identificadas por padrões estéticos, formas de se comunicar e pelos produtos que consomem (MAFFESOLI, 2006). Os membros das tribos partilham de uma paixão por um dado objeto, o qual pode ser um lugar, um 
indivíduo, um produto ou uma marca (COOPER, McLOUGHLIN \& KEATING, 2005; GALVÃO, 2006). Na presente pesquisa, o valor de ligação entre os membros da tribo do dia é o lugar representado por um trecho específico da paia de Ipanema, enquanto o subgênero de charme do gênero musical de black music representa o valor de ligação entre os integrantes da tribo da noite.

Alguns autores dentro das Ciências Sociais discordam da utilização da expressão "tribos urbanas" por acreditarem que esses grupos têm poucas semelhanças com o conceito antropológico de tribos, para esses autores o melhor termo seria "circuitos urbanos" (CAMPOS, 2009; MAGNANI, 2005; TELLES, 2009). Na presente pesquisa, contudo, será utilizada a expressão "tribos urbanas", por esta já ter sido consagrada em Marketing.

\section{Da praia ao baile: tribo do dia e tribo da noite}

As praias guardam grande importância social, cultural e econômica no Brasil, e particularmente no Rio de Janeiro (MAFFESOLI, 2000). No presente estudo, optou-se pelo foco em Ipanema, uma das praias cariocas mais famosas e historicamente importantes (BALSA, 2005). Nenhum outro bairro carioca parece ter tanta tradição cultural quanto Ipanema (CASTRO, 1999). Jaguar (2001) enfatiza que há muito tempo o bairro dita moda, hábitos e costumes para o Brasil e para o mundo. A história do bairro de Ipanema se confunde com a da própria praia que sempre esteve na vanguarda do movimento de liberação das normas de conduta que tinham que ser seguidas nas praias (BALSA, 2005). Foi em Ipanema que Leila Diniz, solteira e grávida, rompeu com os padrões vigentes em 1971 e usou biquíni, um fato marcante para a cultura brasileira (GIACOMINI, 2004). Na mesma praia, em 1973, a modelo Rose Di Primo transformou o biquíni em uma pequena tanga (RIBEIRO et al., 2009)

No início da década de 1970, a instalação de um pier para a construção de um emissário submarino em local próximo à altura da praia em que hoje se encontra o Posto 9, acabou proporcionando melhores condições para a formação de ondas. Com a presença de muitos surfistas, estudantes, artistas e curiosos, rapidamente a praia de se tornou local de encontro da juventude da época (MELO \& FORTES, 2009). Borelli et al. (2009) lembram que o pier de Ipanema tornou-se um grande underground a céu aberto, frequentado por gente de todo tipo. O estilo de vida da praia de Ipanema passou a ser divulgado pela mídia e virou referência para a juventude da época (BUENO, 2005). Atualmente a praia de Ipanema é tida como palco de uma convivência democrática entre intelectuais, artistas, turistas e boêmios, principalmente no trecho entre o Posto 9 e o Posto 10. Ali, rituais sociais de grande diversidade contribuem para a reafirmação da identidade carioca (CASTRO, 1999).

No que diz respeito à tribo da noite, a história da black music deve ser resgatada a partir dos Estados Unidos nos anos 1940, local em que floresceu o blues, cujas raízes estão nas várias formas de manifestação musical dos escravos norte-americanos. Na década de 1970, com a influência do rhythm and blues e do soul, ambos originados a partir do blues tradicional nos anos 1950 e 1960 respectivamente, surge o funky, uma música mais alegre que o soul e vista, por músicos engajados, como uma vertente da música negra capaz de produzir uma arte revolucionária. Mais tarde, por volta do final dos anos 1980, o rap - acrônimo para rhythm and poetry - e o hip hop ganharam espaço entre os subgêneros da black music, sendo atualmente os ritmos predominantes no mercado mundial (HERCHMANN, 2000).

A black music entrou no mercado carioca no início dos anos 1970 (ALVES, 2010). Na periferia do Rio de Janeiro, principalmente por meio do soul, a música black começava a abarcar milhares de jovens, e acompanhando esse fenômeno musical toda uma geração incorporou cabelos afro, visual e 
estilo que passaram a constituir a identidade negra e juvenil brasileira. Ao longo dos anos 1980, vários elementos oriundos do soul foram sendo introduzidos nos bailes cariocas de charme, termo usado para designar a vertente brasileira contemporânea do rhythm and blues (BORELLI et al., 2009). Para Martins (2005), os atuais frequentadores de bailes de charme elegem o baile como espaço de elaboração de suas identidades a partir das relações estabelecidas com seus pares.

Vale notar que a apropriação da música negra americana pelos jovens brasileiros passa por um divisor de águas: o surgimento dos bailes funk cariocas (LIMA, 2002), que sofreram influência tanto do charme quanto do hip hop, além do próprio samba (PALOMBINI, 2010). O tipo de música atualmente conhecido como funk no Rio de Janeiro - que guarda pouco em comum com o funky norte-americano - sofre grande discriminação e é considerado como alienado e de gosto duvidoso pelos adeptos do hip hop e do charme (HERSCHANN, 2000).

\section{Tribos e padrões estéticos}

A dimensão estética tem importância cultural reconhecida para a constituição das sociedades desde o início da consciência humana (VIEIRA, 2007). Nos dias de hoje, a importância da estética corporal é tamanha que homens e mulheres mostram-se dispostos a se submeter a tratamentos e cirurgias plásticas para seguir o padrão estético (RIBEIRO \& SIQUEIRA, 2007). Essa valorização estética do corpo influencia no consumo de produtos que prometam um corpo perfeito esteticamente (COX \& COX, 2002). Para os jovens consumir produtos e serviços que se encaixem nos padrões estéticos faz com que o jovem faça ou não parte de determinados grupos (BORELLI $e t$ al., 2009).

No que se refere a tribos urbanas, Maffesoli (2006) chama de padrão estético uma das facetas que fazem com que tais grupos se reconheçam e estabeleçam união emocional. Para Baumann (2003) essa identidade estética pode se constituir por meio de elementos visuais ou sonoros que podem despertar emoções e a sensação comunhão entre os participantes da tribo.

A despeito do fato de que os parâmetros estéticos intragrupais não podem ser os únicos traços comuns para que um grupo seja considerado tribo, o padrão estético é um dos aspectos principais e mais facilmente identificados de uma tribo (MAFFESOLLI, 2006). Frehse (2006) argumenta que normas de natureza estética e ética promovem vínculos identitários entre os membros de uma tribo. A identidade dos pertencentes a uma tribo urbana é mediada pelo consumo de determinados produtos, promovendo uma distinção não mais classista ou política, porém simbólica e estética (HELAL \& PIEDADE, 2010).

Vieira (2007) ressalta que a forma como uma pessoa se veste não garante que ela faça parte de uma tribo, porém usar roupas dentro do padrão estético adotado pela tribo é um importante passo para que o indivíduo não seja visto como intruso no grupo. Além das roupas, o corte e forma de arrumar o cabelo são fundamentais para os padrões estéticos de algumas tribos urbanas, como os punks, os góticos e os emos (AMARAL, 2007; GIACOMINI, 2004; HELAL \& PIEDADE, 2010). Para Vitelli (2002), independentemente da tribo da qual fazem parte, a dimensão estética é fundamental para os jovens.

Nas tribos urbanas que constituem o foco da presente pesquisa, a estética também parece configurar um aspecto identitário crucial. Para os membros da tribo noturna de black music, por exemplo, é importante a valorização da estética associada à negritude, mesmo que eles próprios não incorporem o "visual black" (SANSONE, 2000). No que diz respeito à tribo do dia, diversos estudos mostram que na praia se sobressai a valorização estética de corpos considerados como perfeitos pelos integrantes do grupo (BUENO, 2005; RIBEIRO et al., 2009). Pereira (2004) acrescenta que o padrão estético valorizado nas praias corresponde aos corpos "malhados" em 
academia e bronzeados.

Deve-se fazer notar que a busca de um padrão estético por tribos urbanas acabam gerando práticas de consumo bem definidas, uma vez que os membros de tais comunidades põem-se a consumir um tipo específico de roupas, cortar o cabelo no mesmo lugar, ingerir o mesmo tipo de alimento, dentre outras coisas (HEWER \& BROWNLIE, 2007).

\section{Tribalismo e consumo}

Pesquisar tribos urbanas por meio de suas práticas de consumo é importante, pois pode revelar o valor que produtos e serviços têm na diferenciação e na coesão desses grupos, evidenciando seus valores de ligação (COVA \& COVA, 2002). Cova (1997) defende que, na pós-modernidade, o consumo de produtos ou serviços não isola um indivíduo, servindo antes como um totem para as tribos primitivas. No mesmo sentido, Hogg e Wilson (2004) afirmam que a sociedade é permeada pelas práticas de consumo como projeções da identidade.

Os bens de consumo têm significativo valor simbólico para os integrantes das tribos urbanas e nelas, frequentemente, o processo de consumo faz parte da própria identidade de seus membros e do grupo como um todo (HELAL \& PIEDADE, 2010). Para Rocha e Barros (2004), o ato de consumir se transformou num fato social capaz de gerar representações coletivas. A importância do consumo para as tribos urbanas é tão grande que comumente se pode associar subculturas de consumo a essas tribos (HEWER \& BROWNLIE, 2007).

Nesse contexto, as organizações produtivas podem ter seus produtos e marcas incorporados à construção dessas identidades grupais (BENGTSSON, OSBERG \& KJELDGAARD, 2005). A compra desses produtos influencia na identidade mesmo que as pessoas não façam uso deles (VANZELLOTTI, 2012).

A nova perspectiva encontra respaldo no valor de ligação que um produto pode promover. Os bens de consumo não têm mais seu significado fixo nem conectado com suas funções utilitárias, uma vez que cada indivíduo pode atribuir diferentes significados para os objetos. Há uma relatividade no valor de ligação do objeto, o que faz com que o mesmo produto possa ter significados diferentes para cada tribo (COVA, 1997). Nesse sentido, Barboza e Silva (2012) enfatizam que só os membros da tribo são capazes de entender o significado de determinado produto para a identidade grupal.

Na pós-modernidade, diante da profusão de tribos urbanas com subculturas específicas, estudos que compreendam o consumo sob um aspecto de coletividade ou de comunidade tornam-se ainda mais importantes para o entendimento dessas novas dinâmicas sociais. Tais mudanças acabam promovendo impactos em inúmeros campos do conhecimento, especialmente na área de Marketing, haja vista sua estreita ligação com atos e práticas de consumo (BONNEMAIZON, COVA \& LOUYOT, 2007; FIRAT \& SHULTZ II, 1997).

Tribos urbanas necessitam de um constante engajamento nos processos de afirmação e consolidação da união entre seus membros. Nesse contexto, a função de marketing em uma organização deve enfatizar, sobretudo, o lançamento de produtos e serviços que facilitem esse agrupamento, propiciando assim o surgimento do chamado "marketing tribal" (COVA, 1996). Firat e Shultz II (1997) alertam que, para trabalhar com marketing tribal, é necessário ser aberto e tolerante às demandas não tradicionais comunicadas pelos consumidores.

A despeito de várias tribos urbanas utilizarem o consumo como forma de afirmação identitária, sem questioná-lo (ROUX, 2007), registram-se posições acadêmicas segundo as quais defende-se que afiliações comunitárias legitimas só podem existir em ambientes não mediados por relações de 
mercado (BENGTSSON, OSTBERG \& KJELGAARD, 2005), e outras para as quais algumas tribos mostram-se resistentes ao consumo (SILVA, COSTA \& CARVALHO, 2010). Mesmo desconsiderando o agenciamento dos pesquisadores, algumas tribos urbanas defendem que existe um abismo entre seus rituais sagrados e a busca do lucro no mundo corporativo, tida como profana (COVA, KOZINETS \& SHANKAR, 2007).

\section{Procedimentos metodológicos}

A etapa de coleta de dados para a pesquisa foi desenvolvida por intermédio de observação participante (MAFFESOLI, 2006) nos locais de reunião das tribos, e de entrevistas semiestruturadas em profundidade com informantes. A seleção dos sujeitos foi realizada por conveniência (VERGARA, 1997). Recorreu-se ao procedimento de snow-balling (AAKER, KUMAR \& DAY, 2004), de maneira que um entrevistado recomendasse outro sujeito de características semelhantes - membro da mesma tribo - até atingir a saturação repetitiva (BODDY, 2005).

Para investigar a tribo do dia, foram selecionadas pessoas que frequentassem costumeiramente a praia de Ipanema entre o Posto 9 e o Posto 10. O filtro usado na seleção se resumia a perguntar se a pessoa costumava ir àquele ponto da praia com frequência. Por frequência entenda-se ao menos uma vez por semana, em semanas com sol. Foram entrevistadas doze pessoas com idades entre $19 \mathrm{e}$ 31 anos. Os entrevistados selecionados para a caracterização da tribo da noite foram ouvintes de um conhecido programa de rádio dedicado à propagação de black music, por meio do qual são promovidos bailes. Todos os entrevistados são frequentadores de bailes de charme. Foram realizadas seis entrevistas em profundidade com os membros da tribo de black music, com idades entre 24 e 40 anos. A diferença no número de sujeitos pesquisados em cada tribo é justificada pelo fato de que a saturação repetitiva foi encontrada mais rapidamente na tribo da noite. Como é de consenso entre os pesquisadores identificados com os métodos qualitativos, a coleta deve abranger o volume de dados necessários para que se atinja a compreensão satisfatória do fenômeno (GUEST, BUNCE \& JOHSON, 2006; VERGARA, 2010). Os pesquisados eram bastante homogêneos no que diz respeito às condições socioeconômicas, todos pertencem a classe média carioca.

A observação mostrou-se fundamental para o estudo, pois permitiu identificar aspectos do ambiente habitado pela tribo, bem como padrões estéticos presentes na comunidade. Conforme recomenda Creswell (2003), elaborou-se um protocolo de observação com base na revisão de literatura. As observações foram realizadas diretamente nos locais onde se concentram as tribos pesquisadas: no caso da tribo da noite, em dois bailes de black music realizados no centro da cidade do Rio de Janeiro; para a tribo do dia, as observações foram realizadas na praia de Ipanema em dias de sol. Cada grupo pesquisado foi observado ao longo de três dias, por um período de pelo menos duas horas.

O roteiro das entrevistas foi elaborado com base na revisão da literatura e nas observações e foi validado por um membro de cada tribo (CRESWELL, 2003). As entrevistas foram feitas em lugares escolhidos de acordo com a conveniência dos informantes; nenhuma entrevista foi realizada na praia ou nos bailes. As entrevistas se estenderam por um período de tempo variável entre uma hora e meia e duas horas, e foram registradas em áudio com consentimento dos entrevistados e posteriormente transcritas (HUNTER, 2002).

As transcrições das entrevistas foram analisadas por meio da técnica de análise de conteúdo clássica (SAMPIERI, COLLADO \& LUCIO, 2006). Foram seguidas as etapas propostas por Hunter (2002): (1) leitura crítica; (2) análise de conteúdo; e (3) classificação de termos e idéias. Os dados coletados por intermédio das observações foram transformados em informações descritivas (CRESWELL, 2003) com o objetivo de fornecer dados para a caracterização do ambiente e dos padrões estéticos 
adotados pelas tribos.

Depois da análise das informações obtidas em cada uma das tribos, foram empreendidos esforços no sentido de comparação entre as tribos do dia e da noite, buscando confrontar padrões estéticos e práticas de consumo adotadas pelas duas tribos urbanas.

Segundo Aaker, Kumar e Day (2004), uma das principais limitações das pesquisas qualitativas origina-se da necessidade de se demandar do pesquisador um elevado grau de sensibilidade para interpretar os dados. Além disso, os resultados das pesquisas qualitativas não podem ser generalizados estatisticamente (SHAO, 2002). No que diz respeito às entrevistas, a limitação advém da possibilidade do entrevistado apresentar verdades parciais com o intuito de camuflar a situação. Para tentar suavizar essa limitação, foi utilizada a observação, a qual, por sua vez, tem como limitações o viés do observador (MALHOTRA, 2006) e o fato de que o pesquisador pode ser visto como intruso - especialmente em tribos -, o que pode modificar o comportamento dos integrantes do grupo (CRESWELL, 2003).

\section{Descrição e interpretação dos achados da pesquisa}

Decidiu-se buscar não apenas descrever as tribos, mas também comparar e interpretar os achados a partir dos seguintes aspectos: como os grupos se autodescrevem, como exploram a estética como elemento de pertencimento e como o consumo contribui para ligação entre os membros de cada um dos grupos.

\section{Autorretrato das tribos}

No início de cada entrevista, buscou-se entender como o informante caracterizaria para um observador externo a tribo da qual faz parte. Como já havia sido apontado pela literatura (MAFFESOLI, 2006), os entrevistados tiveram dificuldade para descrever suas tribos.

Os entrevistados pertencentes à tribo da black music mostraram dúvidas para definir quais estilos musicais poderiam ser considerados como música black. Alguns demonstraram querer se diferenciar de admiradores de outros ritmos que não o charme.

- Eu não sou igual a uma pessoa que curte o atual hip hop... se você for traduzir uma música dessas, o cara está cantando "eu sou um cafetão". Uma pessoa que está cantando isso não tem cultura, isso não é black. (B17)

O DJ (disc-jóquei) Corello, que apresenta um programa de black music em uma rádio, é citado como um importante identificador da música da tribo que é o seu elemento de união. Diversos entrevistados enfatizaram a importância de Corello para os menbros da tribo da black music.

-Tudo que o Corello toca é black ...ele só toca coisa boa (B14)

- O DJ Corello, eu escutava todo dia esse programa. Então eu me amarrava. Acabei ficando curiosa sobre o baile. (B18)

- O Corello trouxe a black music para o Brasil e hoje ele é responsável pela volta desse tipo de música. É o programa dele é fantástico. (B13) 
A análise das entrevistas mostra que os membros da tribo são capazes de reconhecer facilmente pessoas que naquele momento estão no baile, mas que não pertencem à tribo, pelo modo de dançar, de se movimentar e de se comportar.

- Você chega num baile e percebe claramente quem é charmeiro e quem não é. Pelo jeito de dançar. (B18)

- O rapaz que está babando e olhando as meninas dançando não é um charmeiro. Isso não tem nada a ver com feminilidade, masculinidade, homossexualidade ou heterossexualidade... você percebe no olhar quem é charmeiro e quem não é, percebe no tipo de atitude. (B17)

Na tribo da noite foi possível perceber que existe um sentimento muito forte de pertencimento ao grupo. Depoimentos como "eu sou um adorador de black music" ou "vivo black 24 horas por dia" mostram que os membros vivenciam a paixão pela música intensamente e essa paixão ultrapassa o momento e o espaço do baile de charme. No caso da tribo da praia de Ipanema,entretanto, os entrevistados enfatizaram que a conexão com o "momento e espaço praia" tem uma delimitação, é só uma parte do dia no fim de semana, ou seja, com um horizonte de tempo bastante limitado.

Segundo os entrevistados a palavra que melhor resume o sentimento que liga membros da tribo do dia é "amizade". Outros sentimentos parecem se seguir a partir da amizade: a segurança emocional de saber que o grupo "tá sempre ali" ou a segurança de "poder deixar tuas coisas e jogar um frescobol". Os membros da tribo do dia disseram que aquilo que os une não é somente frequentar a praia de Ipanema, mas também o fato de "terem uma vida muito parecida".

- Identificação, né? Porque é gente que, de uma certa forma, funciona como você funciona. Assim, quer dizer, que tem bastante coisa em comum e isso te dá, vamos dizer, uma sensação de segurança. Que você tá andando com gente que pensa como você. (P11)

A cerveja, as conversas, a leitura, o momento de "pegar sol" e as atividades esportivas, tais como surfe, frescobol e futevôlei e "altinha" e até a presença ilegal da maconha foram apontadas como interesses comuns dos membros da tribo. Vários entrevistados utilizaram esses elementos para criar o que eles próprios chamaram de estereótipo do membro da tribo da praia de Ipanema. Alguns entrevistados declararam que não saber jogar vôlei, por exemplo, pode ser motivo para uma pessoa não ser aceita na tribo.

- O grupo da praia surge principalmente por causa do vôlei de praia... Uma galera nem joga, mas que ficava todo mundo ali em volta da rede e ficou amigo de amigo... Tem a cervejinha também. Passei por vários núcleos, mas a praia foi sempre um lugar que eu sempre frequentei. Eles gradualmente têm sido cada vez mais presentes. (P12)

- Sem jogar não dá. Tter uma rede é pro cara um status... Pro cara é o máximo isso aí. (P7)

- Quem é o cara 'in' da praia? . É o cara que joga altinha. Curte vôlei. É o cara que pega onda. É o cara que sai na 'night'. Pô, o cara que fuma um baseado. (P9) 
A praia foi reconhecida por alguns informantes como sendo o valor de ligação do grupo. Ou seja, a praia pode ser considerada como o elemento responsável pela possibilidade dessas pessoas serem consideradas uma tribo (COVA, 1997). Alguns afirmaram que "se não fosse pela praia, não existiria o grupo", e que o grupo pode não fazer sentido em outras situações fora da praia.

\section{A estética como possibilidade de pertencimento}

O conceito de tribos urbanas na chamada pós-modernidade sugere padrões estéticos como uma importante forma de identificação entre seus membros (BAUMAN, 2003; COVA \& COVA, 2002; MAFFESOLI, 2006;). Nas duas tribos estudadas, foi possível destacar a diferenciação de padrões estéticos. Na tribo da praia os corpos parecem semelhantes, trabalhados em academias e queimados de sol, e as pessoas usam o mesmo tipo de roupas, o que faz com que o grupo apresente uma grande homogeneidade. Um informante chegou a definir os membros da tribo como "playmobil", pelo fato de parecerem todos iguais.

Com relação à tribo da noite, foi possível perceber que subsiste grande heterogeneidade física e etária das pessoas que frequentam os bailes de charme. Essa heterogeneidade pode ser um indicador da existência de um elemento emocional como ligação (MAFFESOLI, 2006) entre os membros da tribo, já que uma análise desses indivíduos considerando formas de diferenciação mais tradicionais como os dados demográficos ou econômicos provavelmente não explicaria a formação desse grupo.

A despeito da aparente heterogeneidade, inclusive da cor da pele, os entrevistados demonstraram em seus relatos admiração e afinidade com a estética associada à raça negra, o que faz com que os membros da tribo adotem como padrão estético roupas, acessórios e outros produtos como forma de aproximação com a aparência dos negros. Para os entrevistados, o fato de o produto ser ou não black pode determinar a escolha do carro, das roupas e até diferenciar lugares que eles se dispõem a frequentar. A valorização da estética negra pela tribo de black music havia aparecido no estudo de Sansone (2000). Os informantes afirmam categoricamente que os melhores dançarinos são os de cor da pele negra.

- Se você ouve a música negra, vai ver as pessoas negras dançando... você vê que elas têm um gingado. São muito melhores que eu. (B13, entrevistado de etnia caucasiana)

- Dançar sem jeito é coisa de branco... eles (os negros) têm essa coisa assim no sangue, que é difícil de você imitar. (B15)

Seguir um padrão estético não somente une os membros da tribo como também os afasta de tribos com as quais eles não guardam identificação (VITELLI, 2002). Os entrevistados da tribo da noite usaram expressões tais como "coisa de branco" e "até parece branco" para falar de outras tribos das quais desejam se distanciar.

- Charme é charme... hip hop parece que é música, vamos dizer assim, "de branco". Entendeu? (B13)

- Dentro do estilo existe uma superexposição do corpo... Não vou usar uma camiseta "mamãe-sou-forte" sem estar forte, com esse meu corpinho de branco. (B17) 
Os entrevistados da tribo da praia, também mostraram querer se diferenciar de diversos grupos, alguns negativamente estereotipados, afirmando que na praia de Ipanema existe um padrão estético evidente, e que pessoas desses outros grupos não são encontradas naquele trecho da praia em que se reúne a tribo do dia.

- Aqui eu não vou encontrar 'Barbies' (homossexuais masculinos que praticam fisiculturismo). Eu não vou encontrar 'Pitboys' (jovens lutadores de jiu jitsu e afeitos a confusões). Eu não vou encontrar 'Patricinhas' (meninas de classe alta que se preocupam somente com a aparência). (P9)

- Acho que a aparência, acaba delimitando quem é quem, por mais que você conheça uma mulher de cabelo roxo, pode ser legal, mas ela não vai entrar lá (na tribo da praia). (P2)

Seguindo a definição de Maffesoli (2006) a estética não está relacionada somente com aparência física, pois esta é apenas uma das variáveis que podem compor a estética de um grupo. Nas entrevistas com os membros da tribo do dia, quase sempre os padrões estéticos estiveram atrelados à aparência física, principalmente a corpos malhados e bronzeados, cabelos lisos e roupas "com estilo".

- Pessoas com corpos malhados, bonitas, jovens, enfim, que desfilam. (P4)

Os informantes da tribo da noite deixaram claro que a comunidade black music ultrapassa a questão estética, pois expressa positivamente uma raça sistematicamente marginalizada na sociedade brasileira. Declarando que o chamado "movimento black" é uma forma de expressão da cultura negra, alguns entrevistados revelaram-se preocupados com o engajamento social e declararam que a admiração estética é somente mais um "valor de ligação" (COVA \& COVA, 2002) entre os membros da tribo, não tão importante quanto a afinidade sócio-política.

Para a tribo da noite, a maior abrangência do padrão estético esteve presente nos relatos que apontaram a importância da estética musical e da dança para o grupo. Foi possível perceber que existe um padrão de dança, todos do grupo dançam de forma idêntica, mesmo quem não se conhece dança coreografias conjuntas que parecem ter sido ensaiadas. O ritual coreografado da dança parece colocá-las em comunhão com os demais membros da tribo. As coreografias compõem a atmosfera (MAFFESOLI, 2006) dos encontros da comunidade de black music e despertam admiração e emoção nos membros da comunidade

- Eu cheguei e não precisei falar nada: não perguntei... o cara não me perguntou o nome, não achou tipo que eu estava "dando mole" para ele. Dancei, fiquei dançando o maior tempaço e depois eu fui embora assim. Mas eu dancei com o pessoal ali, e eu senti que realmente conhecia e que estava gostando de dançar aquilo ali. (B14)

\section{Consumo das tribos do dia e da noite}

A partir dos dados de observação participante e entrevistas pôde-se perceber que as duas tribos investigadas têm por prática consumir produtos e serviços com o objetivo de se diferenciar de outros grupos e como forma de promover coesão entre seus membros, conforme apontam Cova e Cova (2002). Na tribo da praia de Ipanema, por exemplo, foi possível notar que o vestuário faz com que certos indivíduos sejam rejeitados pelos membros da tribo. Sungas, biquínis e cangas podem 
funcionar como parâmetro para "selecionar" pessoas que se adéqüem ao perfil do grupo.

- Aparecer de maiô pra dar uma de doida assim... quando vejo umas pessoas com aqueles biquínis grandes, sabe, porque geralmente a galera não usa muito... Pô, aquelas sungas são muito pequenas... fininhas do lado ou coisa assim. Seria bem falho. (P1)

As vestimentas também se mostraram importantes para a identificação das pessoas que fazem parte da tribo da noite, corroborando o estudo de Vieira (2007) que mostrou que a forma como uma pessoa se veste é um dos principais elementos de identificação do grupo ao qual ela pertence. Os depoimentos dos informantes e as observações nos bailes sugerem que o vestuário é um ponto de união entre os membros da comunidade black music.

Assim, no caso da tribo da noite, o vestuário diferencia não apenas a comunidade black music de outros grupos, como também estilos distintos dentro da comunidade. As roupas compradas pelas pessoas que gostam de hip hop estão ligadas ao visual do basquete americano. Nos relatos dos membros da tribo do charme, entretanto, eles fizeram questão de dizer que são "mais elegantes" por não imitarem esse estilo que vem do hip hop.

- Nos caras do hip hop você vê muita coisa com número. Eu já vi num clipe um cara com um cinto assim... calça estilizada... Nós (do charme) não. (B13)

A valorização da elegância no charme fica evidente quando se nota que todos os entrevistados da tribo afirmaram usar suas melhores roupas nos dias de baile. Essa elegância no charme tem raiz no fato de que os primeiros bailes no Rio de Janeiro ocorriam em espaços mais nobres, que serviam de pista para bailes de dança de salão. O termo "elegância" costuma aparecer igualmente nas letras das músicas apreciadas pela tribo.

- Dia de baile é dia de elegância. (B15)

- Se um lixeiro for ao baile depois do trabalho, com certeza, naquele dia, ele vai sair mais elegante do que o usual.(B16)

Alguns autores defendem que a roupa que uma pessoa decide comprar diz muito a respeito de sua identidade (HELAL \& PIEDADE, 2010). Nesse sentido, cabe destacar que entre os membros da tribo da noite é possível notar a diversidade de estilos que marca o velho e o novo charme. Os frequentadores mais antigos se vestem de modo inequivocamente comprometido com a elegância, ao passo que os mais jovens se dizem mais preocupados com o conforto para a dança. Um dos entrevistados mais velhos mostrou-se preocupado com a possibilidade de que a identidade visual do charmeiro se perder com o tempo.

- Identificava-se \{o charmeiro\} através das roupas, até do modo do corte do cabelo, existia uma moda. Hoje, o charme não é tão preocupado com moda... acho uma pena. (B16)

A tentativa de manter a elegância ou estilo dos charmeiros se reflete principalmente no consumo de 
roupas e acessórios. Cabe destacar que alguns produtos considerados elegantes pelos membros da tribo não são tidos como elegantes para serem usados fora do baile.

- Aí um amigo meu me emprestou um sapa-tênis vermelho assim que parecia... em outros lugares iam me chamar de Bozo[um conhecido palhaço que usava sapatos grandes e vermelhos]. (B13)

Os informantes da tribo da noite falam também das blusas de gola rolê, crucifixos dourados, blazeres de padrão xadrez, vestidos longos estampados e sapatos de salto alto. Eles não mencionam a influência da origem americana onde o clima frio é mais adequado a blazeres e golas altas se comparado ao clima quente do Rio de Janeiro. No entanto, um aspecto importante do processo de compra de roupas lembrado por eles é a influencia de amigos, que praticamente delimitam o que deve ou não ser comprado. As amizades também são importantes para a prática de emprestar roupas, comum entre todos os membros da tribo.

- A gente troca muito coisas assim tipo ele me empresta um dia, eu empresto outra coisa para ele, para fazer um estilo que combine com cada um. (B13)

- A gente comprou junto uma calça ... foi ele que comprou, mas a gente sempre sai junto para comprar roupa e tal. (B16)

Foram poucas as observações feitas pelos integrantes da tribo da noite acerca do consumo de outros produtos que não roupas e acessórios. Alguns disseram que não compram carros "de branco", mas sem se aprofundar mais no assunto.

$\mathrm{Na}$ tribo do dia, por outro lado, as associações com consumo parecem ser bem mais variadas: academias de ginástica, biscoitos de polvilho da marca Globo, chá mate gelado da marca Leão, cadeiras de praia e barracas de sol. A despeito da variedade, os produtos mais mencionados pelos entrevistados também se referem às roupas e acessórios da praia: saias, bermudas, bolsas, chinelos, chapéus, biquínis, cordões, pulseiras e óculos escuros, que são diferenciados por seu tamanho: as saias são curtas e os óculos grandes, e que dependem da moda daquele verão. "Estar na moda" parece importante para essa tribo do dia. No entanto, alguns parecem preocupados com um "estilo alternativo" capaz de diferenciar ou quem sabe lançar "uma modinha" nova no espaço não tão democrático da praia e seus padrões estéticos.

- Pode até dizer estilo alternativo. É estilo alternativo, mas não vai comprar nas lojinhas que todo mundo compra. Não gosto. (P11)

- Todo mundo se veste mais ou menos igual. Têm umas diferenças bem sutis, mas não vejo muita diferença. Todo mundo tem o mesmo estilo. (P7)

Outro consumo lembrado pela tribo da praia de Ipanema é o aluguel de cadeiras e barracas na própria praia, junto aos "barraqueiros de sempre" que também vendem as bebidas ali consumidas. Enquanto que, para a tribo da noite, a dança funciona como demarcação de território, para a tribo do dia as cadeiras e barracas alugadas com suas cores ou marcações específicas formam o que os entrevistados chamaram de "fortezinho. $\mathrm{Na}$ observação foi possível perceber que alguns sujeitos chegam correndo para alugar as cadeiras e barracas antes de outras pessoas que vêm de fora: o 
importante é marcar o lugar.

A valorização do corpo pelos integrantes da tribo da praia influencia no consumo dos serviços de academias de ginástica e musculação apontadas como "fundamentais" por alguns entrevistados, que admitem uma forte associação entre "malhar" e frequentar a praia. Lembram que, no inverno, trancam as matriculas nas academias e tornam a procurá-las quando o verão de aproxima. A valorização da aparência saudável não está necessariamente ligada a uma preocupação com a saúde propriamente dita, pois um dos entrevistados assumiu o consumo de hormônios esteróides anabolizantes ("bombas" na linguagem popular) para favorecer a estética corporal quando há pouco tempo para preparar-se para o verão. As "bombas" foram somente uma das drogas lícitas ou ilícitas citadas pela tribo da praia. A maconha e a cerveja apareceram com frequência nos relatos que não pareciam querer esconder o consumo ilícito das "bombas ou da "maconha":

- Não é saúde. É corpo. Tem gente ali que dois meses antes do verão, entra na academia. Começa a malhar, aí toma "bomba" e tal. Aí cresce. Fica com o corpo "sarado". E ai tá pronto pra vir pra praia. Vai pra praia e tal. Passou. E aí... lá é o Carnaval. Ai o cara veio "murcho", e aí dois meses antes do verão seguinte, o cara já tá lá na academia e tal. (P9)

- Mas pô, mas tem o ritualzinho da cerveja também. Volta e meia um ou outro dá uma relaxadinha \{fumar maconha\} ali. Entendeu? Uma galera dá uma relaxadinha ali. Eu não sou usuário não, mas não tenho preconceito. (P8)

Outros produtos relacionados com o padrão estético do corpo tido como perfeito são os bronzeadores corporais e as tatuagens espalhadas por todo o corpo de homens e de mulheres. Observou-se que os protetores solares contêm quase sempre fatores de proteção baixos, e somente são usados protetores mais fortes nas tatuagens recém feitas.

Já na tribo da noite não foi possível encontrar menção a drogas nos discursos dos entrevistados. A observação participante nos bailes mostrou apenas o consumo de variados tipos de bebidas alcoólicas. As drogas são um tipo de consumo que fazem parte de rituais de diversas tribos (MAGNANI, 2005; PIMENTEL et al., 2009). A esse respeito, Costa, Rebolledo e Lopes (2007) afirmam que os membros das tribos subordinam seus interesses aos coletivos, em sua busca de prazer e da felicidade baseada no consumo e na execução de ações orientadas para a fruição do presente, o que pode explicar o consumo de drogas sem preocupação com conseqüências futuras

Até mesmo na hora de se alimentar na praia, os membros da tribo do dia parecem seguir um padrão. Para beber mate gelado, dão preferência aqueles de galão. Quem está com fome costuma optar por biscoitos Globo ou sanduíches naturais. Para os informantes, comer ou beber qualquer outra possibilidade de alimento pode ser um indicador de que a pessoa não pertence àquele grupo. Depois da praia, a tribo segue o ritual de se reunir "no mesmo barzinho de sempre", onde são consumidos cerveja e petiscos até a noite.

A literatura mostra que algumas marcas têm tamanha importância para um grupo que tendem a ser sacralizadas e passam a ser cultuadas pelos membros desse grupo (MARTINELI, 2006). Nesse estudo foi possível perceber evidências de sacralização de pelo menos três marcas pela tribo da praia: Biscoito Globo, Mate Leão (principalmente em galão) e sandálias Havaianas. Para essa tribo consumir esses produtos de outras marcas parece não está em questão: "tem que comer biscoito Globo", "mate de verdade, aquele da praia, só o de galão". No que diz respeito às sandálias Havaianas, França (2010) aponta que a marca já faz parte da cultura brasileira e tem importância na 
representação do país internacionalmente.

\section{Discussão Final}

A estética das tribos urbanas parece ser mais solta e capaz de unir elementos até então separados socialmente por gênero, idade, dimensões econômicas ou étnicas. Conforme apontado por Maffesolli (2006), as características dos ambientes das tribos influenciam na criação de padrões estéticos e de consumo dessas comunidades. No caso da tribo do dia, foi possível perceber que, pelo fato de a praia ser frequentada por pessoas associadas a diferentes tribos, existe a necessidade dos membros da tribo seguirem o mesmo padrão estético e consumirem os mesmos produtos, de modo a se diferenciar de outros indivíduos que podem também comparecer ao espaço público da praia de Ipanema, mas que não fazem parte da tribo. Já nos bailes de charme, ambiente habitado pela tribo da noite, dificilmente há pessoas de outras tribos. Sendo assim, nesse espaço, os membros da tribo da black music parecem não estar muito preocupados em se diferenciar de outros grupos, mas em desenvolver padrões estéticos e comportamentais que aproximem as pessoas da própria tribo.

Outra diferença percebida entre as duas tribos diz respeito ao fato de os membros de uma tribo pertencerem a várias outras tribos, conforme apontou Frehse (2006). Na tribo da praia, foi mais fácil perceber essa característica, pois os sujeitos dessa tribo declararam fazer parte de outras comunidades durante a semana, nas quais eles desempenham papéis diferentes. Para alguns informantes, a tribo da praia representa "uma fuga em grupo" de suas rotinas semanais, já que na praia "tudo é leve", e só existe lugar para "conversas amenas". Os entrevistados da tribo da noite, por sua vez, fizeram questão de relacionar suas identidades individuais com a identidade grupal da tribo, sem jamais comentar espontaneamente a respeito de outras tribos das quais também fazem parte.

Nas duas tribos foi possível notar a fundamental importância dos padrões estéticos. Enquanto na tribo do dia esses padrões estão relacionados principalmente com a aparência de seus membros, que devem manter seus corpos bronzeados e "malhados", na tribo da noite, além da aparência relacionada à "elegância", existe uma permanente preocupação com os padrões estéticos refletidos na dança e na música. Para Borelli et al.(2009) a estética é um dos fatores mais determinantes para decisões relativas a consumo para membros de tribos urbanas.

Como asseveram Hewer e Brownlie (2007), os padrões estéticos seguidos por uma tribo urbana influenciam nas práticas de consumo adotadas por seus membros. As duas tribos aqui estudadas confirmam essa posição. Na tribo da noite, o consumo de roupas e acessórios segue um padrão, e obter a aceitação dos outros membros da tribo sobre o que compram para vestir mostrou-se muito importante. No caso da tribo da praia, evidenciam-se práticas de consumo condicionadas ao padrão da tribo que ocorrem antes da ida à praia, como academias de ginástica e bronzeadores, e durante o momento em que estão na praia, aluguel de cadeiras e barracas, além de biscoites e mate. No que diz respeito á sacralização de bens de consumo (MARTINELI, 2006) foi possível notar que a tribo do dia tende a sacralizar bens de consumo não duráveis e a tribo da noite sacraliza pessoas, como o DJ Corello.

O consumo de drogas lícitas foi observado em ambas as tribos. Entretanto, na tribo da praia o consumo de drogas ilícitas também apareceu como elemento de ligação entre os membros. MacRae (1994) observa que os rituais de consumo de drogas funcionam como agregadores dos membros das tribos. Ainda segundo esses autores para que uma droga seja ritualizada ela deve ser escassa e ter importância reconhecida pelo grupo. As duas tribos parecem ter rituais de grupo como a dança na tribo da noite e esportes praticados na tribo do dia, mas também rituais individualizados de preparação para o pertencimento: o vestuário diferente para ir ao baile charme e a preparação do 
corpo malhado para ir à praia.

Como sugestões para pesquisas futuras, pode-se investigar outras características subculturais associados às tribos urbanas aqui investigadas, tais como mitos e tradições ritualísticas das tribos da praia de Ipanema e da black music. Outras possibilidades de estudos poderiam incluir a comparação o que foi encontrado na tribo da praia de Ipanema com padrões estéticos e práticas de consumo seguidas por tribos de outras praias, bem como comparar os resultados obtidos junto à tribo da black music com outras tribos que também podem ser associadas a comunidades existentes na noite.

\section{Referências}

AAKER, D.; KUMAR, V.; DAY, G. Pesquisa de Marketing. São Paulo: Atlas, 2004.

ALVES, A. Os meios de comunicação brasileiros e o surgimento da black music. Revista Urutágua, v.1, n.22, p. 31-41, 2010.

AMARAL, A. A estética cibergótica na internet: música e sociabilidade na comunicação do MySpace. Comunicação, Mídia e Consumo, v. 4, n. 9, p. 87-103, março 2007.

ARNOULD, E.; THOMPSON, C. Consumer Culture Theory (CCT): Twenty Years of Research. Journal of Consumer Research, v. 31, n.4, p. 868-882, 2005.

BALSA, Marilena. Ipanema de Rua em Rua - do Arpoador ao Jardim de Alah. Rio de Janeiro: Editora Rio (Estácio de Sá), 2005.

BARBOZA, R.; AYROSA, E. Um estudo empírico sobre a construção da identidade social do consumidor de Toy Art. In: ENCONTRO DE MARKETING DA ANPAD, 4, 2010. Anais... Florianópolis, 2010.

BARBOZA, R., SILVA, R. Subcultura Cosplay: a Extensão do Self em um Grupo de Consumo. In: ENCONTRO DE MARKETING DA ANPAD, 5, 2012. Anais...Curitiba, 2012.

BAUMANN, Z. Comunidade: A busca por segurança no mundo atual. Rio de Janeiro: Jorge Zahar Ed., 2003.

BÉHAGUE, G. Globalization/Modernization Rap, Reggae, Rock, or Samba: The Local and the Global in Brazilian Popular Music (1985-95). Latin American Music Review, v. 27, n.1, p. 79-90, 2006.

BENGTSSON, A.; OSTBERG, J.; KJELDGAARD, D. Prisoners in paradise: subcultural resistance to the marketization of tattooing. Consumption, Markets and Culture, v. 8, n. 3, p. 261-274, 2005.

BODDY, C. A rose by any other name may smell as sweet but "group discussion" is not another name for a "focus group" nor should it be. Qualitative Market Research, v. 8, n. 3, p. 248-255, 2005.

BONNEMAIZON, A.; COVA, B.; LOUYOT, M. Relationship marketing in 2015: a Delphi approach. European Management Journal, v. 25, n. 1, p. 50-59, 2007.

BORELLI, S.; ROCHA, R.; OLIVEIRA, R.; LARA, M. Jovens urbanos: ações estético-culturais e novas práticas políticas. Revista Latinoamericana de Ciências Sociales, v. 7, n. 1, p. 375-392, 2009. 
BUENO, Z. Leia o livro, veja o filme, compre o disco: a produção cinematográfica juvenil brasileira na década de 1980. 2005. Tese de Doutorado em Multimeios. Instituto de Artes, Unicamp, Campinas, 2005.

CAMPOS, R. Entre as luzes e as sombras da cidade: visibilidade e invisibilidade no graffiti. Etnográfica, v. 13, n. 1, p. 145-170, maio 2009.

CARVALHO, J.; HEMAIS, M.; MOTTA, P. Do Zen ao Techno: As Tribos de Consumidores e a Música nos Cenários de Serviços. In: ENCONTRO DA ANPAD, 25, 2001. Anais...Campinas: Anpad, 2001.

CASTRO, R. Ela é Carioca. São Paulo: Companhia das Letras, 1999.

CRECHIARO, I.; HALPEN, E.; AYROSA, E.; BARROS, D. Apropriação de Ambientes Físicos de Serviços por Tribos Urbanas: O Caso Casa da Matriz. In: Congresso Nacional de Administração e Ciências Contábeis, 3, 2012. Anais... Rio de Janeiro: FACC, 2012.

COOPER,S.;McLOUGHLIN,D.;KEATING,A. Individual and neo-tribal consumption: tales from the Simpsons of Springfield. Journal of Consumer Behaviour,v.4,n.5,p.330-344, 2005.

COSTA, M.; REBOLlEDO, N.; LOPES, L. Uso de drogas no Chile: pesquisa documental e bibliográfica. Revista Eletrônica Saúde Mental Álcool e Drogas, v. 3, n.1, 2007.

COVA, B. Community and Consumption: Towards a Defenition of the "Linking Value", European Journal of Marketing, v.31, n.3/4, p. 297-316, 1997.

. What postmodernism means to marketing managers. European Management Journal, v. 14, n. 5, p. 494-499, October 1996.

; COVA, V. Tribal marketing: the tribalization of society and its impact on the conduct of marketing. European Journal of Marketing, v.36, n.5/6, p. 595-620, 2002.

; KOZINETS, R.; SHANKAR, A. Tribes, Inc.: the new world of tribalism. In: COVA, B.; KOZINETS, R.; SHANKAR, A. (Eds.) Consumer tribes. Burlington, MA: ButterworthHeineman, 2007. p. 3-26.

COX, D.; COX, A. Beyond first impressions: The effects of repeated exposure on consumer liking of visually complex and simple product designs. Journal of the Academy of Marketing Science, v. 30, n. 2, p.119-130, 2002.

CRESWELL, J. Quality inquiry and research design: choosing among five traditions. Thousand Oaks: Sage, 2003.

DIONÍSIO, P.; LEAL, C.; MOUTINHO, L. Fandom affiliation and tribal behaviour: a sports marketing application. Qualitative Market Research, v. 11, n. 1, p. 17-39, 2008.

FIRAT, A .; SHULTZ II, C. From Segmentation to Fragmentation - Markets and Marketing strategy in the Postmodern Era. European Journal of Marketing, v.31, n.3/4, 1997.

FRANÇA, M. Das areias para o mundo. In: O GLOBO - Marcas dos cariocas, 17 de dezembro de 2010. p. 20-21.

FREHSE, F. As realidades que as "tribos urbanas" criam. Revista Brasileira de Ciências Sociais, v. 21, n. 60, p. 171-174, 2006.

GALVÃO, F. Fragmentação do sujeito, experiência mercantilizada e centralidade do consumo na 
modernidade. UNIrevista, v. 1, n. 3, p. 1-11, 2006.

GIACOMINI, S. O corpo como cultura e a cultura do corpo: uma explosão de significados. PHYSIS: Revista de Saúde Coletiva, v. 14, n. 2, p. 406-416, 2004.

GUEST, G.; BUNCE, A.; JOHSON, L. How Many Interviews Are Enough? : An Experiment with Data Saturation and Variability. Field Mothods, v.18, n.1, p.59-82, 2006.

HASENBALG, C.; SILVA, N. Relações Raciais no Brasil Contemporâneo. Rio de Janeiro: Rio Fundo Editorial. 1992.

HELAL, D.; PIEDADE, A. Modernos ou pós-modernos? Um estudo exploratório sobre o comportamento de consumo dos emos em Belo Horizonte. Revista Comunicação Mídia e Consumo, v.7, n. 18, p. 171-192, 2010.

HERSCHMANN, M. O Funk e o hip hop invadem a cena. Rio de Janeiro: Ed. UFRJ, 2000.

HEWER, P.; BROWNLIE, D. Cultures of consumption of car aficionados Aesthetics and consumption communities. International Journal of Sociology and Social Policy,

v. 27, n. 3/4, p. 106-119, 2007.

HOGG, G.; WILSON, E. Does he take sugar? The disabled consumer and identity. British Academy of Management Conference Proceedings. St. Andrews, Scotland, August 2004.

HUNTER, S. Foundations of Marketing Theory: toward a general theory of marketing. London: Sharpe, 2002.

JAGUAR. Ipanema - Se não me falha a memória. Rio de Janeiro: Relume Dumará, 2001.

JURISIC, B.; AZEVEDO, A. Building customer-brand relationships in the mobile communications market: The role of brand tribalism and brand reputation. Journal of Brands Management, v.18, p.349-366, 2011.

LIMA, A. Funkeiros, Timbaleiros e Pagodeiros: Notas sobre juventude e musica negra na cidade de Salvador. Cadernos Cedes, v. 22, n. 57, p. 77-96, 2002.

MacRAE, E. A abordagem Etnográfica do Uso de Drogas. In: MESQUITA, F.; BASTOS, F. (Eds.) Drogas e AIDS - Estratégia de Redução de Danos. São Paulo: Hucitec, 1994.

MAFFESOLI, M. O Tempo das Tribos. O declínio do individualismo nas sociedades de Massa. 4. ed. Rio de Janeiro: Forense Universitária, 2006.

. Tribal aesthetic. In: COVA, B.; KOZINETS, R.; SHANKAR, A. (Eds.) Consumer tribes. Burlington, MA: Butterworth-Heineman, 2007. p. 27-34.

MAGNANI, J. Os circuitos dos jovens urbanos. Tempo Social, v. 17, n. 2, p. 173-205, 2005.

MALHOTRA, N. Pesquisa de Marketing. 4. ed. Porto Alegre, Bookman, 2006.

MARTINELI, F. A Sacralização da Marca e a Pirataria: comunicação e sociabilidade nas práticas de consumo de bens piratas. Dissertação de Mestrado em Comunicação Social. Universidade Federal do Rio de Janeiro, Programa de Pós-Graduação em Comunicação e Cultura da Escola de Comunicação, 2006 
MARTINS, C. Os bailes de charme: espaços de elaboração de identidades juvenis. Última Década, n. 22, p. 39-62, 2005.

McCRACKEN, G. Cultura e Consumo. Rio de Janeiro: Mauad, 2003.

MELO, V.; FORTES, R. O surfe no cinema e a sociedade brasileira na transição dos anos 70/80. Revista Brasileira de Educação Física e Esportes, v. 23, n.3, p. 283-296, 2009.

PALOMBINI, C. Notes of the historiography of música soul and funk carioca. Haol, n. 23, p. 99$106,2010$.

PEREIRA, C. O corpo carioca desnudado. Revista Estudos Feministas, v. 12, n. 1, p.333-337, 2004.

PEREIRA, S. AYROSA, E. Estigma, consumo e identidade de gênero entre gays. In: ENCONTRO DE MARKETING DA ANPAD, 4, 2010. Anais... Florianópolis, 2010.

PIMENTEL, C.; GOUVEIA, V.; SANTANA, N.; CHAVES, W.; RODRIGUES, C. Preferência musical e risco de suicídio entre jovens. Jornal Brasileiro de Psiquiatria, v. 58, n.1, p. 26-33, 2009.

RIBEIRO, C.; SIQUEIRA,V. O novo homem na mídia: ressignificações por homens docentes. Estudos Feministas, v.15, n.1, p. 217-241, 2007

RIBEIRO, M.; SANCHES, R.; VICENTINI, C.; COSTA, S.; BURUQUE-RAMOS, J. 1772 Qualidade, conforto e estética na moda praia. In: Congresso Internacional de Pesquisa em Design, 5, 2009. Anais...Bauru: CIPED, 2009.

ROCHA, E.; BARROS, C. Dimensões culturais do marketing: teoria antropológica, etnografia e comportamento do consumidor. Revista de Administração de Empresas, v. 46, n. 4, p. 36-47, 2006.

ROUX, D. La résistance du consommateur: proposition d'un cadre d'analyse. Recherche et Applications en Marketing, v. 22, n. 4, 2007. p. 59-80.

SAMPIERI, R.; COLLADO, C.; LUCIO, P. Metodologia de pesquisa. 3. ed. São Paulo: McGrawHill, 2006.

SANSONE, L. Os objetos da identidade negra: consumo mercantilização, globalização e a criação de culturas negras na Brasil. Mana, v. 6, n. 1, p. 87-119, 2000.

SCHOUTEN, J.; ALEXANDER, J. Subcultures of consumption: an ethnography of the new bikers. Journal of Consumer Research, v. 22, n. 1, p. 43-61, 1995.

SEGABINAZZI, R.; NIQUE, W.; PINTO, D. O estilo de vida da tribo do surf e a cultura de consumo que a envolve. In: ENCONTRO DA ANPAD, 35, 2011. Anais...Rio de Janeiro: Anpad, 2011.

SCHAU, H.; MUÑIZ, A.; ARNOULD, E. How brand community practices create value. Journal of Marketing, v.73, n. 5, p.30-51, 2009.

SHAO, A. Marketing Research: An aid to decision marketing. 2. ed. Cincinnati: Thomson Learning, 2002.

SILVA, T.; COSTA, A.; CARVALHO, J. Tribalismo e Resistência ao Consumo: Etnografia de um 
Circuito Urbano de Parkour. In: Encontro de Marketing da Anpad, 4, 2010. Anais... Florianópolis: Anpad, 2010.

TELLES, V. Ilegalismos urbanos e a cidade. Novos Estudos CEBRAP,n.84,p.153-173, 2009.

VANZELLOTTI, C. Comprar, ter e ser: um estudo sobre maquiagens. In: ENCONTRO DA ANPAD, 36, 2012. Anais... Rio de Janeiro: Anpad, 2012.

VERGARA, S. Projetos e Relatórios de Pesquisa em Administração. São Paulo: Atlas, 2010.

VIEIRA, G. A atuação do jornalismo frente à formação de novas tribos urbanas. I; Congresso Brasileiro de Ciência da Comunicação, 30, 2007. Anais... Santos: Intercom, 2007.

VIANNA, H. Funk e cultura popular carioca. Estudos Históricos, v.3, n. 6, p. 244-253, 1990.

VITELLI, C. Estação adolescência: identidade na estética do consumo. Dissertação de Mestrado em Educação. Universidade Federal do Rio grande do Sul, 2002. 